This item was submitted to Loughborough's Institutional Repository by the author and is made available under the following Creative Commons Licence conditions.

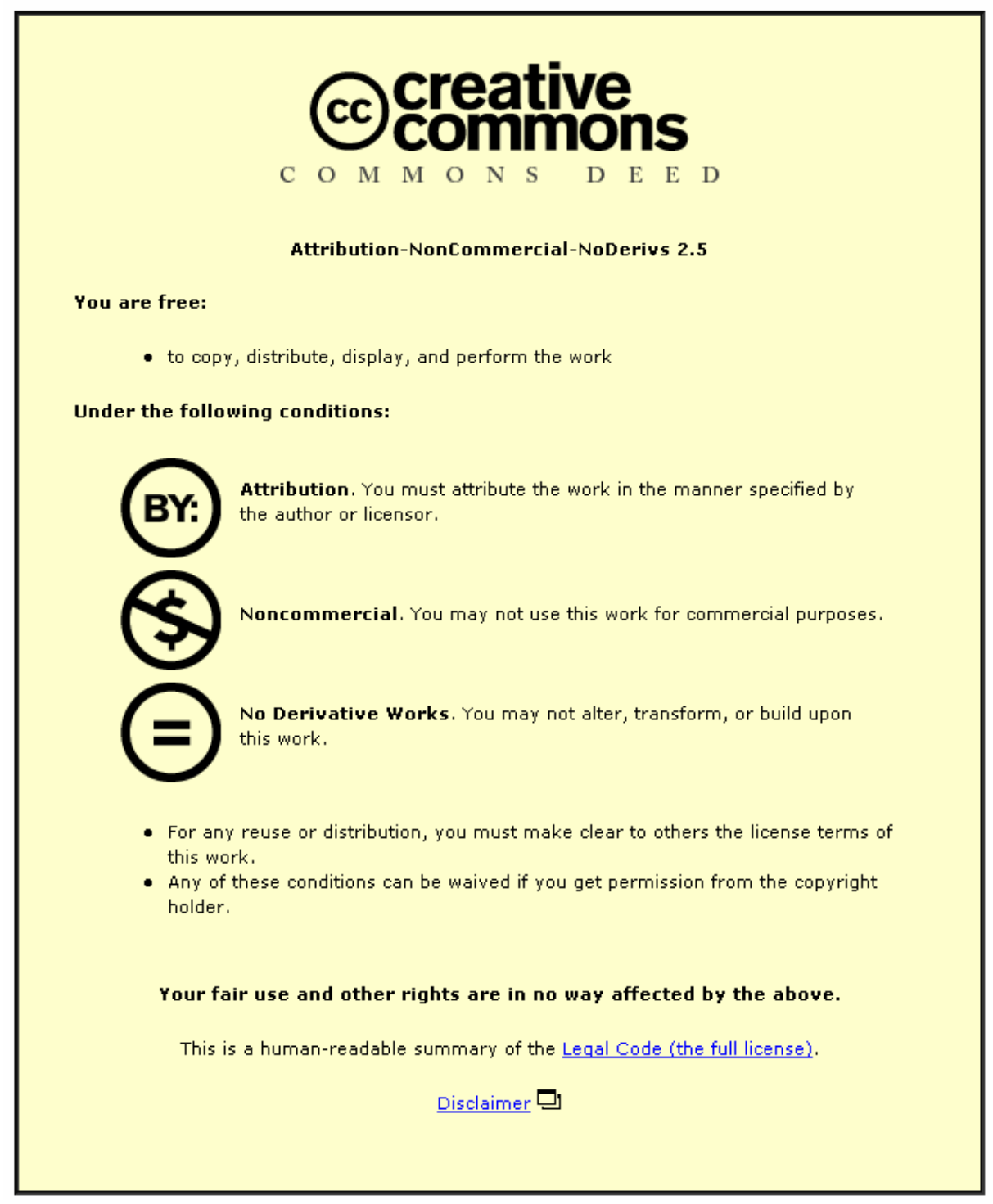

For the full text of this licence, please go to: http://creativecommons.org/licenses/by-nc-nd/2.5/ 


\title{
Examining the political and practical reality of bus-based Real Time Passenger Information
}

\author{
Miss N Holdsworth, Dr M P Enoch* and Dr S G Ison \\ Transport Studies Group \\ Department of Civil and Building Engineering \\ Loughborough University \\ Leicestershire LE11 3TU, UK
}

\begin{abstract}
Enhancing the bus experience through improved information provision is a key element of the UK Government's transport policy as stated in 'A New Deal for Transport: Better for Everyone' (DETR, 1998). There are several ways of doing this, but one in particular - Real Time Passenger Information (RTPI) - has often been seen by local authorities as the way forward. RTPI is perceived to reassure passengers waiting for a bus by reducing the uncertainty of when (and even whether) the bus will arrive, thus encouraging patronage and benefiting the public transport operator through increased revenue and the local authority, by promoting social inclusion and achieving a modal shift. RTPI also provides an important tool for operators by allowing them to monitor services and refine their schedules.
\end{abstract}

\footnotetext{
${ }^{*}$ Corresponding author: Tel: +44 (0)1509 223408; Fax: +44 (0)1509 223981; Email: m.p.enoch@lboro.ac.uk.
} 
The aim of this paper is to understand the reasons for implementing RTPI in the bus sector and to determine the key issues impacting on the likely success of such a policy. Consequently, a case study approach has been adopted that investigated the experiences of two provincial towns in the UK namely, Warrington in the North West, which is preparing to implement RTPI and Loughborough in the East Midlands, which has deployed RTPI in recent years. The paper suggests that whilst it is unclear whether RTPI has resulted in an increase in bus patronage it is considered to be most effective when combined as part of a package of measures. It is intended that the findings from the two case studies will reveal lessons of relevance to authorities, world-wide, contemplating the introduction of RTPI

\section{Introduction}

Since the publication of the UK Government's 'A New Deal for Transport: Better for Everyone' (DETR, 1998) increasing the use of the bus has been seen as a key way of assisting in the reduction of car use and its associated impacts on the economy, society and the environment. Achieving a mode shift is somewhat problematic, not least given the perceived image of the bus in the UK. In order to address this issue it can be argued that a step change in the 'quality of the bus product' is required. One possible way of directly addressing passenger perception of reliability and poor quality information, is Real Time Passenger Information. To date however, the evidence is unclear as to whether RTPI does actually enhance public transport service provision. 
The aim of this paper therefore, is to investigate the use of RTPI in two provincial UK towns namely Warrington and Loughborough and to draw lessons of relevance to other towns and cities contemplating the implementation of a RTPI system.

\section{The need for better bus information}

In the UK between 1952 and 2004, bus passenger kilometres fell from 92 billion to 48 billion, whilst car use increased more than ten-fold, from 58 billion passenger kilometres a year to 679 billion passenger kilometres (DfT, 2005). Whilst more recently the decline in bus patronage appears to have stabilised dominance of the private car continues. This period of decline in the bus industry can be viewed against a background of various ownership, regulatory and organisational changes to the industry's structure. In particular, the 1985 Transport Act (in Scotland, the Transport (Scotland) Act 1989) deregulated and privatised the bus industry in a bid to reduce costs and subsidies, introduce competition, and as a result lead to higher service levels and lower fares. Overall results were mixed (Preston, 2003 pp.159 -160), but one particular weakness has been information provision due to the redistribution of responsibility between operators and local authorities and the competition between operators preventing the publication of easily understandable information (Balcombe and Vance, 1998). This is despite the crucial role passenger information provision plays in promoting high quality efficient bus services and providing an attractive alternative to the private car (Department of Transport, 1996 and the TAS Partnership, 2000). This 
suggests that poor information provision has been a contributing factor in the decline of bus use.

Information on bus journeys and services available therefore needs to be accessible and understandable and should satisfy the basic requirements to know where and when the services operate (Balcombe and Vance, 1998). The TAS Partnership (2000) found that $86 \%$ of the urban bus passengers questioned had never referred to a detailed timetable as the majority of these passengers used 'frequent service' routes. Passengers on these routes require simple and clear service information as opposed to 'precise departure times and similar information [which] may be of little relevance to passengers' (TAS Partnership, 2000 s.4.4.1). Furthermore, a large part of the community has little or no experience of travelling by bus and is unable to obtain or understand the conventional information provided, again highlighting the need for basic service information.

It is widely recognised that traditional methods of information provision can be complemented by innovations in technology (Balcombe and Vance, 1998). The UK Government's ten-year plan (DETR, 2000), therefore outlined plans to expand Traveline to create a more comprehensive electronic transport information service, Transport Direct, which began providing people with a 'one-stop shop' allowing journeys, routes and prices to be compared for all modes of transport from January 2005. Under the plan, in March 2002, £20 million was allocated to fund 19 real time bus passenger information schemes across England (DfT, 2002). 


\section{Real Time Passenger Information}

Real Time Passenger Information (RTPI) is a means of marketing public transport and providing electronic travel information to the users of public transport in 'real time' via a range of sources, such as bus stops, stations, on vehicles and via the telephone or Internet (Department of Transport, 1996). In general, RTPI systems work by using Global Positioning System (GPS) Satellite Navigation equipment installed on each bus to accurately calculate position. This locational information is then broadcast via a radio network to a central control centre which compares the actual journey times to a published timetable. The control centre then calculates an actual time of arrival of the bus at stops along a route and relays this information to the displays at stops and on buses (Action Information Management, not dated).

In recent years RTPI has been introduced as a new feature to increase the attractiveness, accessibility, punctuality and utility of public transport, especially the bus, as an alternative to the use of the private car (Schweiger, 2003). The realisation that RTPI has the potential to promote public confidence in bus services and therefore increase patronage has resulted in the recent interest and investment by local authorities in Real Time Information systems for bus services across England.

Studies on the impact of RTPI systems are limited (Schweiger, 2003). Research into the business case for bus real-time passenger information by Basford, Burke and Pickett (2003) identified that there is a lack of robust quantitative investigation into the effects of the implementation of such 
schemes. Bishop (1999) suggested that 'investment in the integration of [RTPI systems] across agencies is very difficult to justify on a strictly commercial basis as little quantifiable data exists from which to assess the incremental costs and revenues associated'. Similar points are made by Okunieff (1997) and Tyson (2003), while the TAS Partnership (2000) states that it is difficult to accurately apportion costs and financial benefits between the organisations involved. There is a widespread belief however that RTPI systems have the potential to provide extensive benefits to bus passengers, bus operators and Local Transport Authorities (Basford et al 2003).

RTPI has the potential to increase customer satisfaction by enhancing the waiting experience, which in turn contributes to the entire experience (Basford et al 2003). Nakamura et al (1998) conducted research into passenger frustration levels whilst waiting for buses and concluded that RTPI reduced anxiety levels, (providing the system was reliable) because it provided reassurance that the bus would arrive, while a study by Lehtonen and Kulmala (2002) in Helsinki found that RTPI increased the level of comfort experienced by bus travellers. Mishalani et al (2000) found that passengers experience greater discomfort waiting for a bus than the time spent on a bus, partly because of the uncertainty associated with the arrival time of the next bus. RTPI has the potential to reduce this discomfort, since it reduces the disutility of waiting time and enables them to make more informed travel decisions or conduct time-filling diversionary activities without the fear of missing the bus (Horbury, 1999). Improved pre-journey planning capabilities provided by RTPI via mobile phones and the Internet are perceived to enable passengers to 
arrive at the stop just before the bus is due meaning that RTPI may one day be viewed by passengers as 'a necessary part of their travel experiences' (Schweiger, 2003 p.3).

However, evidence on whether RTPI increases patronage is varied. Studies on the London Underground reported by Kelland (2003) and in Ottawa, Canada by Suen and Geehan (1986) illustrate that RTPI can increase passenger demand by up to 10\%. Meanwhile DfT (2003) reports evidence from London that routes increased patronage by $1 \%$ following the introduction of RTPI, while a figure of $5 \%$ for a route in Liverpool. Finally, it states that the STOPWATCH at stop RTPI system (also in London) showed that $81 \%$ of bus passengers found the information useful and 3.7\% of users used the service more as a result.

Conversely, Schweiger (2003) found that while customer reactions towards RTPI were positive, agencies have been unable to report a definite increase in patronage as a direct consequence of implementing RTPI. Harrison et al (1998) supports this view, noting that it is often a combination of measures that increase ridership making it difficult to ascertain the exact contribution of RTPI. For instance, RTPI has been implemented as part of a package of measures in a number of Quality Bus Partnership schemes, for example the SMART scheme in Merseyside in the North West, Superoute 66 in Ipswich, East Anglia, and the Showcase bus routes in the West Midlands, all in the UK. Since services began in these areas ridership has increased. Holland (2000) reported that 33 new bus passenger journeys had been generated on Superoute 
66 as a result of its website and that $12 \%$ of these new journeys were trips that would not have been previously made. Again however, it is difficult to ascertain the effect of RTPI upon this growth.

Any increases in ridership as a result of RTPI improving customer service, enhancing the journey experience and consequently the public perception of public transport, benefits local authorities in promoting public transport, thereby aiding a modal shift and as such achieving national policy objectives (Basford et al 2003). RTPI further contributes to achieving these objectives since it helps to promote social inclusion by balancing the advantages and disadvantages of using public transport use with those associated with private modes (Bishop, 1999). There are also network management benefits for operators associated with RTPI - namely that it can assist the management and optimisation of operations and services and help deliver bus priority, fleet management, bus journey time-savings and improved reliability which are important for local authorities (Department of Transport, 1996; Okunieff, 1997; Schweiger, 2003).

Experience to date in the UK has demonstrated that neither local authorities nor operators alone can make the business case to justify investment in RTPI (Basford et al 2003). It is recognised however that both parties can realise benefits from such systems and as a result, partnerships have developed with each partner contributing to the costs of the system (Department of Transport, 1996). It is felt that without the full commitment and support of the operator, 
the scheme will not succeed and the benefits will not be achieved (TAS Partnership, 2000).

The following section outlines the two towns in the UK studied as part of the research, namely Warrington (Cheshire) in the North West of England and Loughborough (Leicestershire) in the East Midlands.

\section{Overview of the two towns}

As stated the two areas studied were Warrington and Loughborough,. Warrington has been preparing to implement RTPI across its bus network and Loughborough, has a RTPI that has been in operation for a period of time and has been extended since its initial deployment therefore there is a wide range of data available on RTPI schemes.

Warrington, Cheshire, UK

Warrington is a 'New Town' located between the conurbations of Greater Manchester and Merseyside. It covers an area of 43,527 acres and over recent years has experienced rapid growth in industry, commerce and housing. Many businesses and major retailers are located out of town, resulting in a development pattern that is difficult to serve by traditional public transport schemes. See Table 1 for key 2001 census figures.

Warrington Borough Council (WBC), was identified by the Department of Transport Local Government and the Regions in 2002 as a Centre of Excellence for implementing technology for Urban Traffic Management and 
Control (UTMC) (DTLR, 2002). RTPI has been the focus of UTMC development in Warrington over the past few years, with a view to provide information displays at bus stops, shopping centres, major public transport interchanges, large employers and business parks across the Borough. By Spring 2004 the Council aimed for the first phase of the scheme to go live and funded the installation of RTPI equipment at 150 bus shelters, costing around $£ 1.5$ million; resulting in RTPI being the most expensive of the UTMC subsystems. The next stage involved equipping an additional 75 bus shelters so that 225 shelters across the Borough now have RTPI dissemination capabilities.

There are a number of bus operators in the Warrington area, the largest and most predominant being Warrington Borough Transport Ltd (WBT), owned by WBC. As such, WBT has been the principal partner involved in the implementation of the scheme, with the Council equipping 110 vehicles of WBT’s bus fleet with RTPI equipment.

Loughborough, Leicestershire, UK

Loughborough is a free-standing town, located between two large urban centres of Leicester and Nottingham. See Table 1 for key data. Since Autumn 2000 a Real Time Passenger Information system, star trak, has been operating in Loughborough. This system is operated by Leicester City Council on behalf of the star trak partnership, which was conceived through the Leicester and Loughborough Quality Bus Partnerships and includes Leicester County Council along with the three bus operating companies (star trak, 2004). 
The initial impetus behind the RTPI scheme came from the local authority, Each of the partners however plays a part in the management and funding of the system and is committed to expanding the schemes as and when funding is available. From the outset the partnership aimed to implement the system across the county so passenger perceptions were monitored before and after the system was introduced. Since the initial implementation of RTPI, the schemes have expanded; the first major expansion being in the first year of deployment when operator First Bus Leicester approached the Council with a desire to equip a new bus fleet with on-bus real time equipment. Similar expansion has occurred incrementally in Loughborough to the extent that a high proportion of the bus operators fleet is now fitted with star trak apparatus.

More recently, the star trak system has been advanced to provide a text message facility, star text sms, to enable passengers to obtain real time information at bus stops via their mobile telephones. The system works by the passenger typing the code into their mobile telephone and texting it to the number shown on the display. A reply is then returned to the mobile phone giving the actual arrival time of the next bus at the stop. The cost of sending the message is the same as normal text message rates plus there is a cost to receive a return message. The facility is currently experiencing thousands of hits a week.

\section{Insert Table 1 here}




\section{Research method}

Four in-depth interviews were undertaken two in Warrington and two in Loughborough (where RTPI was already well established). The objective of the interviews was to explore the attitudes to RTPI and understand the reasons for implementing RTPI in the bus industry and to ascertain the key issues impacting upon the business case.

The interviews took place between January and March 2004 and were conducted with the Urban Traffic Management and Control manager at Warrington Borough Council (WBC) and the Managing Director of Warrington Borough Transport (WBT). Interviews in Loughborough were conducted with the Leicester City Council Project Manager for RTPI (in Loughborough, Leicester and Leicestershire) and the Head of Development for the major bus operator in Loughborough. To enhance the data collected from the interviews, each respondent was asked to complete a questionnaire, ranking the ten most important impacts on the business case for RTPI.

\section{Findings and discussion: experiences in Warrington and Loughborough}

This section details the key issues that arose in the discussions in Warrington and Loughborough.

\section{Warrington}


Motivations and expected benefits

The UTMC programme in Warrington is heavily focused upon RTPI since it is perceived to bring many wide-ranging benefits to passengers, operators and the Authority.

Warrington Borough Council (WBC) believed RTPI to have the potential to improve passengers' perceptions of public transport and therefore generate new bus passengers. "There are some quite widely held perceptions about what RTPI does for the bus traveller...in terms of heightening the perception of the service...lessening the perception of any delay...and... getting new users on board...because information is immediately to hand”.

As for the bus operators, WBC expected them to gain from operational benefits such as enhanced scheduling and network management. "It will allow the bus operators to look at what they are doing with their timetabling...they'll be able to scrutinise the timetables more accurately to see where they can sharpen up their operations”.

For the Authority itself, "It's quite a good tool from our perspective as well...we will be able to identify problems across the network quickly...by looking at trends in the data...if it is a bottleneck that affects the buses...it is a bottleneck that affects general traffic".

When asked what benefits WBT thought RTPI would bring, they replied in terms of the benefits they perceived WBC to hold regarding the system, focusing on the following: "I presume the local authority chose to implement 
RTPI because reliable information at the bus stops would be of so much value to customers that they actually generate extra bus use...and that the historic information generated by RTPI systems can be used to demonstrate the case for...and introduce bus priority measures...such as extra green time for buses at traffic lights...which in turn will result in more reliable buses”.

The operational aspects RTPI provides for the bus inspectors was also raised as an issue. "If the inspectors know the bus is going to be late they can do some remedial measure such as put on another bus...it will help with the immediate supervisory task...and in principle...improve reaction times”.

When WBT was asked what benefits RTPI would provide though, it was unable to identify any specific benefits and displayed an indifferent attitude towards the system, suggesting that it hasn't accepted a proactive role in the scheme. "In a way it almost doesn't matter what my opinion is...all we will do is to try our best to harness and have the technology to promote it...and to help the Borough Council...we'll do all we can to push it out there”.

WBT believes that modern technology such as RTPI will create a quality image for bus travel, thereby benefiting existing passengers, but is sceptical over whether RTPI alone will generate increased bus use since increased patronage is very difficult to achieve in the bus industry. "I'm prepared to accept the argument that customers are reassured by RTPI...so I think the existing customers will find it useful... The truth is that increases in patronage in the bus industry are very very difficult to generate... a one per cent or two 
per cent increase in patronage would be a wonderful achievement...five per cent across the whole network would be unheard of”.

The operator felt that other initiatives could be implemented that would have a greater impact on generating patronage, such as bus priority and junction improvement measures. "If you said to me...here is one million pounds...would you like to spend it on RTPI or spend it on introducing bus lanes and making junction improvements to speed buses up...my instinct would be to spend it on bus lanes and the road junctions rather than in the hope that the information at bus stops would attract more passengers... real bus priority to allow us to deliver a higher frequency at lower fares...that would definitely get people back on buses...and so would some of the harder measures such as road pricing and workplace car parking charges”. This reinforces the views of Harrison et al (1998) and Schweiger (2003) in that it is a combination of measures that improve ridership, therefore it is difficult to determine the effect of the deployment of RTPI on any increase and for operators to justify any significant expenditure on RTPI.

WBT therefore believes that the only way RTPI can increase bus use is if the Local Authority use the data to identify bottlenecks in the network and therefore provide bus priority measures. This will improve bus service reliability and increase frequency, which in turn will generate increased bus use.

With regard to operational management; WBT is able to identify a possible benefit of RTPI in that it will enable them to refine their schedules to improve 
reliability, which in turn will release resources to allow higher frequencies or reduce pressure on bus fares. This is a benefit recognised in studies by Wilkinson et al (1998) and Schweiger (2003) which identified that information from RTPI systems can be used to modify service frequency, result in an adjustment in the distribution and number of buses deployed and refine the schedules to more accurately meet travel demand. Modifications to scheduling and frequency are among the most common service changes that bus operators can make to improve service effectiveness (Balcombe et al, 2004). “More reliable bus services...in principle will reduce pressure on bus fares...whether or not it succeeds in doing that it remains to be seen”.

The Traffic Commissioners are the regulators of the bus industry and they permit buses to depart within an operating bracket of 'up to one minute early, or up to five minutes late' (VOSA, 2004). RTPI will enable WBT to gather journey information network wide, providing instant information identifying the proportion of services which fall within this tolerance. Consequently, WBT considers RTPI as a useful tool to help submit information to the Traffic Commissioner and demonstrate their compliance with the target. Research by Basford, Burke and Pickett (2003) also found that RTPI can assist in avoiding penalties from the Traffic Commissioners. "Our regulator is very strong in terms of compliance... and RTPI helps us to comply with their target...so it is a practical benefit for us”.

Up to the date of the interview, WBC had spent $£ 1.5$ million of the LTP package on RTPI, resulting in RTPI being the most expensive of the UTMC 
subsystems, simply because of the amount of equipment that is involved; the cost of equipping a bus shelter is $£ 4000$ - $£ 4500$ and a bus is $£ 3000$. Additional equipment WBC has funded includes software, the radio base station and the radio licences. The Local Authority believes that the WBT can recognise the benefits of RTPI but are reluctant to acknowledge any benefits and contribute towards the costs. "We've tried to gain contributions from the bus companies...but other than a few thousand pound here and there for the minor elements...the bus companies are very reluctant to contribute... I think WBT can recognise the benefits... they just don't want to acknowledge them."

\section{Concerns}

WBT noted it was concerned about the accuracy and reliability of the system because any inaccuracies will affect the reliability of the data submitted to the Traffic Commissioner. "For the system to be useful it has got to work one hundred per cent of the time”. WBC is not concerned however about the reliability and accuracy of the data due to the way in which the system functions. "If we were ever in any doubt about what a sign is saying we can communicate directly with it and request back what it is exactly saying...so we can diagnose any faults that might be occurring”.

WBC had initial concerns about the confidentiality of the data collected. As a result, the Council and WBT have agreed to keep all data confidential to enable WBT to "use it constructively for [its] benefit". Furthermore, WBT is concerned that the system will simply identify the extent to which the buses are reliably late. However, WBC believes that this will also affect themselves 
since the public will then be able to identify where improvements to the network are needed. "I think that it is a double edged sword ...because once people realise that the buses are running three...four...five minutes late...they will start putting pressure on the operators to justify why they are always late...but that can flip around on the local authority...putting them under the spotlight because a certain junction isn't performing”.

\section{Lessons learnt}

When asked on lessons for other organisations, the Authority pointed out that a good relationship with the operator is essential in order to successfully implement RTPI and therefore they recommended any other authority implementing RTPI to fully involve the operators from the outset. "The advice I'd give to a local authority would be to tackle the operators first before embarking on the scheme...”.

WBT agreed that the specification of the system and roles and responsibilities of both the local authority and the operators should be established from the outset of the project. It felt that implementing RTPI has had a positive and constructive effect upon their relationship with the Authority, resulting in both parties gaining increased understanding of the pressures and difficulties faced by each other. In retrospect, it appears that a stronger, more positive partnership would exist if a partnership had been developed earlier in the project. 
The questionnaire, about the key impacts on the business case for RTPI (Table 2), shows that the Authority's ambition for RTPI is for increased service provision and quality via improved scheduling and schedule adherence. This is intended to reinforce the passenger base and hopefully increase it. Effective transport management is key to achieving this, both in terms of fleet operation and highway management. Furthermore, increasing bus use, will contribute to achieving a modal shift, which is a key objective of the LTP. In comparison, the factors that WBT consider important in order to demonstrate the business case for RTPI include improved service reliability and frequency as a result of improved scheduling and enhanced network management (including bus priority).

The Authority believes that if a generic business case for RTPI had been proven and a study had been conducted regarding the benefits of RTPI, WBT would have acknowledged the benefits and played a more proactive role in implementing the scheme. "There are lots of other RTPI systems out there...but nobody has done a comprehensive study on it and reached conclusions about what the public actually think about it and how it has benefited bus companies in terms of their operations and where there has been an increase in patronage”. In this sense, WBC feels it has struggled when implementing the system: “we've fallen foul where other people haven't done this before”. It also believes further encouragement is necessary for the operators. Therefore as part of the scheme's implementation, the Council is conducting a 'before and after monitoring study' to try and put a business case together and demonstrate where the benefits are. 
As previously mentioned, the Authority acknowledges the potential benefit of RTPI in generating new trips and users, however after discussions with WBT it recognises that it is very difficult to increase ridership and as such any increase will be marginal. "I'd like to think that it would result in an increase in passenger numbers...the problem is identifying how much because I believe it would be a very small increase...apparently it's very difficult to generate growth in terms of bus patronage”.

Following discussions, the Authority notes that "WBT would consider it a worthwhile project if it resulted in a one to one and half per cent increase in sustained patronage...it doesn't see any fluctuations on patronage”. But, the Council believes that by providing information via RTPI at the point of purchase, for example at work or at home, it will generate a new market for bus users. "My perception is that if you can introduce a well conceived system that provides accurate and timely information at the point of purchase...at the stop but also away from the stops at a PC in the workplace or at a PC at home...then it could well be that you open up a completely different market”.

This not only reinforces the view of Horbury (1999) with regard to the ability to make informed travel decisions, but also the findings of Bishop (1999) that information reduces the waiting time and therefore the journey time of using public transport and consequently balances the advantages and disadvantages of using public transport with those related to private modes.

The Council is currently considering displaying RTPI screens in schools and offices. Secondary schools are the age group they feel are the most important 
to capture in order to encourage the pupils to perceive buses as a quality service before they are old enough to learn to drive. Meanwhile it is intended that large employers will install displays at their offices and fund the equipment as part of the public transport improvements they are obliged to implement through the planning process. This is in line with new advice from the DfT recommending that local employers contribute to the funding of UTMC systems, on the basis that easier and more pleasant working environments will assist in staff recruitment and retention (Crawford, 2004). Schools are expected to try to secure some external funding to pilot an RTPI project.

A further point with regard to the location of RTPI displays is whether they are more beneficial on heavily used high frequency routes or in rural areas with low service frequencies. The DETR (1999 s.8.4) (1998) suggests that on the busy routes, the buses may be so frequent that passengers do not need to consult a timetable and can simply 'turn up and get on' whereas in rural areas this is not possible and therefore good, clear, easily available information, such as RTPI is needed. Despite this, from a commercial viewpoint WBT considers RTPI to be more useful on high frequency, heavily used routes because it believes these routes provide the most potential to increase patronage. "The general view is that it is best to cultivate the strongest route...where there are the most passengers...such as main line heavily used routes...it's easier to gain an increase in patronage on a big town centre rather than on a rural route". 


\section{Loughborough}

This section details the key issues resulting from the interviews with a major Loughborough bus operator and Leicester City Council.

\section{Motivations and Expected benefits}

In-depth interviews with both the bus operator and the Authority identified that the prime reason for implementing RTPI was to improve bus services in an attempt to provide a realistic mode choice. Prior to implementation, customer surveys identified unreliability and the lack of confidence in the printed timetables as being amongst the worst aspects of bus use. The Authority therefore implemented RTPI with the intention of improving the image and perceptions of bus services, thereby promoting sustainable transport and encouraging a modal shift from the private car. "There was a need to improve the image and perceptions of bus services...buses have a poor image...being dirty and late”.

The main benefit of RTPI is perceived to be the pacifying role it plays for existing customers, providing reassurance that the bus will arrive. "RTPI reassures the passengers waiting at stops and probably plays a role in maintaining existing passengers". This reflects the findings of Schwieger (2003) that 'at minimum, real-time bus arrival information systems assist in the maintenance of ridership'.

Contrary to the aspirations of WBT however, the bus operator has found that RTPI does not improve reliability, one of the customer's top priorities for 
public transport, although it is considered to improve the perception of reliability, reduce anxiety and enable passengers to make more informed choices when making travel decisions. It was stated that "RTPI doesn't improve reliability since our buses are still stuck in traffic jams...but without it...passengers are unaware of what is happening and this creates anxiety and increases the perception of waiting time...they feel as though they are waiting twice as long”.

Nakamura et al (1998) agreed, finding that RTPI reduced the frustration levels of passengers waiting for a bus. RTPI is believed to increase the level of comfort experienced by passengers whilst waiting for a bus (Lehtonen and Kulmala, 2002) and enables them to make more informed decisions and better use of their time whilst waiting (Horbury, 1999 and Mishalani et al, 2000). In turn, these benefits enhance the journey experience, improve customer service and increase passenger satisfaction (Basford et al 2003).

The Local Authority undertook a 'before and after monitoring' study of the star trak system, focussing on passenger perceptions of bus use. Results highlighted that since deploying RTPI, services were perceived to be more regular, with a better quality service and a greater number of passengers (especially women) feel safe and secure whilst waiting at bus stops. These findings confirm the research by Nakamura et al (1998), Lehtonen and Kulmala (2002) Basford et al (2003) and Schweiger (2003).

Traffic congestion causes unreliable traffic patterns and this makes bus scheduling problematic since it affects the frequency and reliability of 
services. The bus operator however is able to use the information from the RTPI system as an operational tool to assist in managing and refining the schedule and as an observational tool identifying areas where bus priority is needed. Information is also used when submitting data to the Traffic Commissioner. "The information from the system can be used to identify regular delays and can therefore be used to adjust the timetable and improve journey times... it also shows where traffic signal priority is needed...this is a real benefit to drivers”.

Since the deployment of RTPI, certain routes operated in Loughborough have grown significantly, with the frequency increasing from every thirty minutes to every ten minutes. However, neither Leicester City Council nor the bus operator believe that RTPI results in an increase in patronage. "I'm not sure that it actually encourages passenger numbers to increase...the prime purpose of RTPI is to benefit existing customers". This is partly because the star trak system was implemented as part of a package of measures, in conjunction with new buses and bus stop improvements. The Local Authority states therefore that it is difficult to attribute any growth in patronage to RTPI alone. This again supports the findings of the interviews in Warrington and the views of Harrison et al (1998) and Schweiger (2003). “Although RTPI has had an effect upon this growth...it is difficult to quantify and disaggregate the benefits since there are also many other influential factors... At the end of the day...there is probably a weak business case for RTPI...alone it would not give a business case”. 
The business case for operators and local authorities is very different (Basford et al 2003). Local authorities need to achieve wider policies formulated by central government and councillors and as such the business case is less important, whereas operators aim to achieve an increase in patronage and a commercial return on their investment. "The bottom line for operators is...will they get back all the money they put in and more".

The questionnaire, dealing with the key issues raised by RTPI (Table 2), identifies that the priority issues for the Council are policy related. Achieving a modal shift (an objective of the LTP and national policy) is the key aim for RTPI by increasing passenger satisfaction and improving scheduling and service reliability. Further issues of importance are the promotion of social inclusion and meeting local needs. The primary issues identified by the bus operator focused heavily on the passenger. The bus operator cites the main issues as being reduced passenger waiting time, resulting in an improved waiting experience that in turn helps to maintain and increase use by existing passengers. The extent to which new passengers can be attracted to the bus is also a key impact as this contributes to achieving a modal shift.

The Authority recognises the need for RTPI at the point of use and as such have actively encouraged the involvement of major employers, and those organisations located at important public facilities, in the RTPI scheme. In partnership with the Authority, companies in Loughborough have funded the information displays near their plant as part of their Travel Plan, which is a condition of the Section 106 Agreement under the Town and Country 
Planning Act 1990. "It is very important for people to have information available to them away from the bus stop...the SMS facility has proved very popular as have the displays located at the hospitals in Leicester".

Lessons learnt

Both the bus operator and Leicester City Council believe RTPI has proved to be a successful venture despite the amount of time and effort the scheme entails. They recommended specifying the system accurately prior to embarking on the project and allocating sufficient time to change the system as the timetable changes. "Be careful when specifying the system...do not underestimate the amount of work involved... RTPI is a model of reality...implementing it takes time...but is worthwhile”.

It is also considered important to allocate time to test the system before it goes live in order to avoid bad publicity and the scheme being discredited if the system fails. "Allocate time to test the system before it goes live...the worst thing that could happen is to switch on the system and it not work...this is likely to result in negative public perceptions and a poor reputation of the scheme”.

The bus operator believes that both the local authority and bus operator need to be fully involved in the project. "For a scheme to work...one hundred per cent commitment is needed from all parties involved... but sadly a lot of bus companies are being dragged into RTPI schemes...without having their hearts in it...this results in problems such as operators not allocating the buses 
installed with equipment to the right routes”. The Council supports this view, noting that "Operators need to get involved at the beginning...partnership working is essential to this scheme...the operators shouldn't feel as though the system is being imposed upon them...[because] there are benefits to be achieved”.

\section{Comparison of the Key Issues Identified in the Questionnaire}

Table 2 combines the results of each questionnaire and compares the differences in the key issues ranked by each party's response to the RTPI impacts questionnaire.

\section{Insert Table 2}

The variety of key impacts ranked by each organisation illustrates that RTPI is capable of bringing a range of benefits and can be utilised to reflect the interest of the parties involved. This spectrum makes it difficult to determine any one specific impact of a general RTPI system.

Predictably, as noted earlier, a number of the key impacts for the bus operator are passenger focused, whilst the impacts for Leicester City Council are policy oriented. This suggests that their partnership is working successfully since both parties have objectives which complement each other and strive towards achieving the same goal; " to improve the image and perceptions of bus services and benefit customers". Interestingly, in Warrington, it is the Council and not the bus company that focuses directly on the passenger. The only impact associated with the passenger is existing passenger retention, and this 
is only ranked tenth (in a selection of the top ten) by WBT. This is in sharp contrast with the Loughborough bus operator who rank this factor as the second most important impact.

WBT selected a set of factors that are associated with achieving operational improvement and this outcome can be perceived in one of two ways. The bus company could be considered to be adopting an approach with respect to RTPI that is similar to many other public transport operators; that the prime reason for implementing Automatic Vehicle Location (AVL) systems being to improve operational efficiency. Once this benefit has been realised, operators then begin to display interest in providing RTPI to customers (Schweiger, 2003). On the other hand, however, the issues ranked by WBT could also reflect the situation of an organisation undergoing cultural change. WBC also identified the importance of improving bus service administration and supervision, further suggesting that this is an issue.

WBT cited both gaining improved information on driver performance and increased driver job satisfaction as important benefits of deploying RTPI. Interestingly, however, drivers at WBT identified that many perceive the system as a performance-monitoring tool, referring to it as 'spy in cab'. The drivers believe that the system will require them to account for why they are not running to time and will consequently have a negative effect on their jobs.

WBC and WBT share similar goals for RTPI. They expect to gain significant network management benefits from the system by using the data to refine 
schedules and to identify bottlenecks in the network to help justify where and why junction improvements and bus priority are needed.

The interview with the Loughborough bus operator revealed that it recognised that RTPI can identify where bus priority is needed, however, it does not rank it as a primary function of RTPI in the questionnaire. Leicester City Council only set it as the ninth most important impact. In the interviews, the bus operator commented that it uses RTPI as an operational tool to assist it in managing and refining the schedule, as an observational tool identifying areas where bus priority is needed and as a compliance tool to submit information to the Traffic Commissioner. However, these factors are not ranked as key issues impacting on the business case in the questionnaire and as such, they do not support the findings by Schweiger (2003) that the prime reasons for operators deploying RTPI systems are to achieve improvements in operational efficiency. Interestingly, operational improvements appear to be a greater priority for Leicester City Council.

Surprisingly, despite the expense of RTPI systems and the limited ability to attribute specific quantifiable benefits to RTPI, no organisation identified as important, the cost factors that impact on the business case, the associated capital, maintenance and operational costs and costs to passengers. This reinforces the findings by Schweiger (2003 p.3) that 'many agencies are not aware of the expense of operating and maintaining their real-time systems, because communication costs vary widely based on the type of communication and the way the communication is charged.' 
The nature of bus companies means they must operate under tight commercial budgets and as such costs are always an important issue. In the questionnaire however neither bus operator identified costs as an important factor, suggesting that their financial contributions to the systems have been minimal and that the schemes rely heavily upon finance from the local authorities. In this sense, there is a risk that the benefits of partnership working cannot be maximised. If the system is successful, the operators are likely to gain many benefits, however it is unlikely that they will acknowledge these benefits as this will validate the need to make increased financial contributions towards the scheme.

\section{Conclusions}

Whilst this paper has focussed on two highly specific UK localities and their experiences with RPTI there are important lessons that can be learnt which are applicable internationally. The lessons learnt can be divided into three main areas namely the benefits of RPTI, the opportunities they afford and words of caution.

In terms of the benefits, technology such as a RTPI system can be all important in creating an improved image for the bus sector. In addition, what is clear from the interviews, both from the Local Authority and bus operator perspective is that a major objective of providing RPTI is to increase bus patronage. This is to be commended since increased bus patronage will have the dual effect of tackling traffic congestion and also increasing bus operator income. 
In terms of the opportunities RPTI affords, it can be used as an operational tool for operators in terms of schedule adherence monitoring and reporting, schedule refinement and fleet management, identifying bottlenecks in the network and therefore aid network management. There are thus potential efficiency gains to be made. From an operator perspective RTPI provides invaluable information in terms of timetabling, whilst it provides Local Authorities with the ability to speedily identify problems across the route network. Thus RTPI can be used as a congestion management tool to identify bottlenecks and as a mechanism for reinforcing the case for bus priority measures. Equally, there is clearly a need for authorities to consider the potential of RTPI. This could mean using such a system in such places as schools, universities and offices. As such, the business community could in fact be a source of funding for such initiatives.

As for words of caution, RPTI would appear to be more effective if included as part of an overall strategy. As stated, 'good information will not sell bad services' (Balcombe and Vance, 1998 p.26). Therefore it can be assumed that certain conditions must exist for RTPI to be used as a successful marketing tool to promote bus travel. Clearly the overall strategy requires measures to address the issue of congestion. The reason is that congestion will hinder RTPI and result in the system informing passengers that the buses are 'reliably late' and as such the introduction of RTPI may also require the implementation of various measures, most notably the provision of extensive bus priority schemes. In addition, RTPI is likely to prove more effective if service improvements are also achieved. 
Whilst a benefit from RPTI is the potential increase in bus patronage a note of caution is that the evidence obtained as part of this study it is by no means certain that the introduction of RPTI will generate an increase in bus patronage on its own.

There is also a need to sell the benefits of RTPI to potential bus users since accurate information reduces the waiting time and therefore the overall journey time of using public transport. In saying this there is a need to ensure that the data provided by RTPI is both reliable and accurate.

The introduction of a RTPI system requires cooperation between the various parties. A partnership between the local authority and operator is considered essential in order to ensure the scheme is successful and that both parties can realise the benefits. This has a significant impact on the business case for RTPI since the costs and benefits are shared and as a result it could allow RTPI to be implemented in conjunction with other measures, set in the context of policies for other modes of transport. The introduction of a RTPI system may require joint funding. From the research undertaken however it would appear that bus operators have been somewhat reluctant to contribute towards the provision of RTPI. This is potentially an area that any Authority considering the introduction of RTPI would need to be aware of.

Finally in terms of caution, the Local Authority may perceive RTPI as providing improved information any Authority considering the implementation of such a system must account for the fact that bus drivers 
may see RTPI as a performance monitoring device, which may impact on job satisfaction.

Overall there is clearly much research to be undertaken into the likely impact of the implementation of such technology, not least since there is a belief that RTPI systems have the potential to provide extensive benefits to bus passengers, bus operators, Local Authorities and via reduced congestion to the economy as a whole.

\section{References}

Action Information Management. (not dated). Real Solutions for the Real World. Wiltshire, UK, Action Information Management Ltd.

Balcombe, R.J., Mackett, R., Paulley, N., Preston, J., Shires, J., Titheridge, H., Wardman, M., White, P. (2004). The demand for public transport: a practical guide. Transport Research Laboratory Report 593. Crowthorne, UK, Transport Research Laboratory.

Balcombe, R.J., Vance, C.E. (1998). Information for bus passengers: a study of needs and priorities. Transport Research Laboratory Report 330. Crowthorne, UK, Transport Research Laboratory.

Basford, L., Burke, C., Pickett, M. (2003). Bus Real-Time Passenger Information Business Case Research. Transport Research Laboratory Project Report PR/T/148/02 for the UK Department for Transport. 
Bishop, M. (1999). A bold approach to the use and integration of real-time public transport passenger information in a multi-modal and multi-agency environment. Presented at the $4^{\text {th }}$ International Conference of ITS Australia, Adelaide. Canberra, Australia, Intelligent Transport Systems Australia.

Crawford, D. (2004). All grown up. Surveyor, 191(5770), 11 March, 18-20.

Department for Transport, Local Government and the Regions (DTLR) (UK). (2002). Centres of Excellence for Integrated Transport Planning. London, DTLR.

Department for Transport (DfT). (UK) (2002). Transport Ten Year Plan 2000: Delivering better transport - progress report. London, The Stationery Office.

Department for Transport (DfT) (UK) (2003). Public Transport Information, Traffic Advisory Leaflet 7/03, London, Traffic Advisory Unit, DfT, December.

Department for Transport (UK) (2005) Transport Statistics Great Britain 2005, London, The Stationery Office, October.

Department of the Environment, Transport and the Regions (DETR) (UK). (1998). A New Deal for Transport: Better for Everyone, Cm 3950, London, DETR, The Stationery Office, July.

Department of the Environment, Transport and the Regions (DETR) (UK). (2000). Transport 2010: the 10-Year plan. London, DETR, The Stationery Office. 
Department of Transport (DoT) (UK) (1996). Better Information For Bus Passengers A Guide To Good Practice. London, DoT.

Harrison, S., Henderson, G., Humphreys, E., Smith A. (1998). Quality bus corridors and green routes: can they achieve a public perception of 'permanence' of bus services? Proceedings of Seminar F: Public Transport Planning and Operations, European Transport Conference, Loughborough, UK, 14-18 September. London, PTRC Education and Research Services Ltd.

Holland, R. (2000). Superoute 66 Live! - the impact of providing real-time information on the Internet. Proceedings of Seminar E: The Planning and Management of Public Transport Systems, European Transport Conference, Cambridge, UK, 11-13 September. London, PTRC Education and Research Services Ltd.

Horbury, A. (1999). Guidelines for specifying automatic vehicle location and real-time information systems using current best practice. Transport Reviews, 19(4), 331-351.

Kelland J (2003) Information Overload: The Effective Preparation of Data for Real Time Services. IQ Conference on Real Time Passenger Information Services for Transport. 25-26 September, London.

Lehtonen, M. Kulmala, R. (2002). The benefits of a pilot implementation of public transport signal priorities and real-time passenger information. Presented at the $81^{\text {st }}$ Annual Meeting of the Transportation Research Board, Washington DC, January. 
Lyons, G., Harman, R., Austin, J., Duff, A. (2001). Traveller Information Systems Research: A Review and Recommendations for Transport Direct. Prepared for the UK Department for Transport, Local Government and the Regions, London, August.

Mishalani, R., McCord, M., Lee, S. (2000). The value of real-time bus arrival information under various supply and demand characteristics. Presented at the $10^{\text {th }}$ Meeting of ITS America, Washington DC, Ohio State University, USA.

Nakamura, F., Babaski, Y., Konda, Y. (1998). Analysis on the effects of real time bus service information provision - Experimental evaluation of bus service information provision via Internet. Proceedings of the $5^{\text {th }}$ World Congress on Intelligent Transport Systems held in Seoul, ROK. Brussels, Belgium, ITS Congress Association.

Office of National Statistics (2001). Census 2001: Summary Statistics about

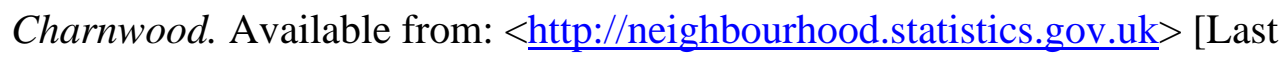
accessed 08/09/06]

Office of National Statistics (2001). Census 2001: Summary Statistics about Warrington. Available from: < $\underline{\text { http://neighbourhood.statistics.gov.uk }>\text { [Last }}$ accessed 08/09/06]

Okunieff, P. (1997). AVL Systems for Bus Transit: Synthesis of Transit Practice 24. Transit Cooperative Research Program, Transportation Research Board, Washington DC, USA, National Academy Press. 
Preston, J. (2003). A 'Thoroughbred' in the Making? The Bus Industry Under Labour. IN: Docherty, I., Shaw, J. Eds. A New Deal for Transport? Oxford, Blackwell Publishing Ltd, 158-174.

Schweiger, C.L. (2003). Real-Time Bus Arrival Information Systems: Synthesis of Transit Practice 48. Transit Cooperative Research Program, Transportation Research Board of the National Academies, Washington, D.C. The National Academies.

star trak (2004). The star trak Partners. Who are we? star trak. Available from: < http://www.star-trak.co.uk/> [Last accessed 08/09/06]

The TAS Partnership Limited. (2000). Quality Bus Infrastructure: a manual and guide. London, Landor Publishing Limited.

Tyson W (2003). Do the Figures Stand-Up? Building a Business Case for Real Time Information. IQ Conference on Real Time Passenger Information Services for Transport. 25-26 September, London.

Vehicle and Operator Services Agency (VOSA) (UK) (2004). Practice Direction: Standards for local bus services, VOSA, November. Available from: < http://www.vosa.gov.uk/> [Last accessed 08/09/06]

Wilkinson, I., Perrett, K., Pickett, M., Wedlock, M., Daugherty, G. (1998). Review of telematics relevant to public transport. Transport Research Laboratory Report 342. Berkshire, UK, Transport Research Laboratory. 


\begin{tabular}{|c|c|c|}
\hline & Warrington & Loughborough \\
\hline Population & 191,080 & $153,462 *$ \\
\hline $\begin{array}{l}\text { Employed (percentage of resident } \\
\text { population) }\end{array}$ & $63.6 \%$ & $61.1 \%$ \\
\hline $\begin{array}{l}\text { Unemployed (percentage of resident } \\
\text { population) }\end{array}$ & $2.9 \%$ & $2.6 \%$ \\
\hline $\begin{array}{l}\text { Have no car or van (percentage of } \\
\text { resident population) }\end{array}$ & $20.9 \%$ & $19.4 \%$ \\
\hline $\begin{array}{l}\text { Have two or more cars or vans } \\
\text { (percentage of resident population) }\end{array}$ & $35.7 \%$ & $35.7 \%$ \\
\hline
\end{tabular}

*Charnwood

Table 1: Key data for Warrington and Loughborough (ONS, 2001). 
Issues:

WBC WBT LCC Bus Op

- Journey time-savings

6

- Reduced number of buses required to operate service

- Avoidance of penalties from the Traffic 5 Commissioner

- Improved service regularity

- Improved service reliability

- Improved schedule adherence and improved scheduling

- Enhanced network management, including increased bus priority

- Fuel cost reductions

- Existing passenger retention

- Increase in use by existing passengers

- Generation of passengers

- Increased passenger satisfaction

- Improved journey planning capabilities

- Reduced passenger waiting time resulting in an improved waiting experience

- Promotion of public transport through journey timesavings

- Moving towards a modal shift

- Compliance with national policy

- Compliance with LTP objectives

- Meeting local needs

- Promotion of social inclusion

- Achieving environmental targets

- Less unscheduled overtime (drivers)

- Automatic updating of fare stages

- Costs of system, capital, maintenance and operating costs

- Improvements in bus service administration and supervision

- Improved information on vehicle performance

- Faster reaction times to problems on the network

- Improved driver working conditions, resulting in increased job satisfaction and reduced driver turnover

- Improved information on driver performance

Cost of information to passengers

Table 2 A comparison of the key issues raised by RTPI. 